\title{
DISCUSSIONS ON ETHNICITY AND SOCIAL CAPITAL IN THE LITERATURE ON MALAYSIAN CONTEXT: A REVIEW
}

\author{
Aliye Nur Kelesoglu* \& Mala Rajo Sathian** \\ *First author, **Corresponding author \\ Department of Southeast Asian Studies \\ University of Malaya \\ Kuala Lumpur, Malaysia \\ (asarica88@gmail.com,malarajo@um.edu.my) \\ DOI: https://doi.org/10.22452/jati.vol24no2.3
}

\begin{abstract}
Despite the vast amount of research on ethnic integration, ethnocentrism, and social capital in the Malaysian literature, there is a growing need to scrutinise comparatively the findings of the studies which have been carried out so far. This paper examines the impact of ethnicity on interethnic relations by reviewing the relevant literature related to social capital and inter-ethnic relations in Malaysia. In order to investigate the different aspects of inter-ethnic relations of Malaysians, the empirical contributions reviewed in the present paper are from three academic disciplines: (i) media studies, (ii) urban studies; and (iii) sociology. Researchers in media studies have discussed the virtual dimension of inter-ethnic relations taking place in online social networking sites whereas urban studies have focused on the actual relationships between Malaysians in different urban settings. Sociological studies, on the other hand, have examined the socialisation processes of Malaysians across different ethnic groups and their racial bridging social capitals. The overall findings of these studies indicate that strong ethnic identities impede bridging social capital, trust among Malaysians and the social solidarity of Malaysians while reinforcing the bonding social capital and in-group solidarity within ethnic groups.
\end{abstract}

Keywords: ethnicity, social capital, inter-ethnic relations, Malaysia, identity

\section{Introduction}

The multi-ethnic, multi-religious and multi-lingual attributes of Malaysian society paved the way in recent years for a greater focus to be placed on the 
concept of social capital in the literature on the Malaysian context. Several studies in a range of academic disciplines, including sociology, urban studies and media studies, have examined the social capital of Malaysia. The concept is of importance in terms of examining the social connectedness of community members and the quality of democratic governance (Putnam, Leonardi \& Nonetti, 1993; Putnam, 2000). Previous studies of social capital which have been conducted in different country contexts have indicated that higher levels of social capital in communities lead to social solidarity, higher levels of trust and active civic life, and better democratic performance. In contrast, a low level of social capital causes social segregation and conflicts between diverse social groups (Brehm \& Rahn, 1997; Hall, 1999; Levi, 1996; Paxton, 2006, 2007; Putnam, Leonardi \& Nonetti, 1993).

Many western theorists have claimed that ethnic, religious and linguistic homogeneity plays a crucial role in the formation of social capital, solidarity and a well-functioning democracy (see Hefner [2001]) and empirical studies have supported this view (Alesina \& La Ferrara, 2000, 2002; Costa \& Kahn, 2003; Delhey \& Newton, 2005; Putnam, 2007). Putnam (2007) pointed out that ethnic diversity leads to social isolation, declining social solidarity and reduced levels of trust. From this perspective, plural societies which are ethnically, religiously and/or linguistically heterogeneous would be more likely to face struggles in building and maintaining social solidarity, so their social capital can be expected to be at lower levels.

Malaysia is considered as a plural society in the sense that it is divided along ethnic and religious lines, in addition to its significant multi-racial and multi-religious characteristics (Farouk \& Zaini, 2007). This attribute of the community has drawn the attention of scholars from various disciplines, and they have endeavoured to comprehend the underlying reasons and possible solutions for this ethnic division. The aim of this current paper is, therefore, to review the recent empirical and theoretical studies related to social capital and inter-ethnic relations in Malaysia and consider the empirical contributions of the studies from the three different academic disciplines.

The studies were reviewed using a qualitative approach. We determined three principal themes: (i) the virtual/online dimension of inter-ethnic relations; (ii) the actual, face-to-face dimension of inter-ethnic relations in the immediate social settings; and (iii) the relationships between micro-level inter-ethnic interactions and macro-level dynamics, such as the ethnic identity formation in the Malaysian social reality. Related to these themes, the primary studies on which this paper focuses were conducted in the context of three different academic disciplines: media studies, urban studies and sociology. 
Media studies have examined the virtual dimension of inter-ethnic relations at the individual level by focusing on social networking platforms and the diversity or heterogeneity of social ties. On the other hand, urban studies have investigated the actual face-to-face dimension of social relations between Malaysians. Both have predominantly argued that meaningful contact and constant interactions between ethnicities at the individual level help to build social capital between different ethnic groups. In contrast, studies in sociology have discussed the impacts of the level of social capital on the identity building of Malaysians.

The social capital concept is used overwhelmingly with a positive connotation in the social sciences literature. However, social capital has a 'dark side' (Ostrom, 2000). The strong ties, high internal solidarity and trust among group members might be problematic for outgroup members. Therefore, the 'bonding' and 'bridging' social capital dichotomy of Putnam (2000) was widely accepted by scholars to distinguish the different attributes of the social capital concept. Bonding social capital refers to the high in-group cooperation, loyalty and solidarity inside the group, but can also lead to out-group antagonism and the exclusion of outsiders. Bridging social capital, however, indicates outwardlooking ties encompassing diverse social cleavages and multi-faceted identities. It should be noted that, in this paper, social capital and bridging social capital concepts are used interchangeably, whereas bonding social capital is used to emphasise the negative characteristic of social capital.

Inter-ethnic relations in Malaysia have long been discussed in the literature in terms of participation in neighbourhood activities or the social interaction preferences of non-ethnics. However, it is hoped that this paper will provide a deeper understanding of inter-ethnic trust and meaningful contact between Malaysians and social capital in the Malaysian literature by comparing the findings of relevant studies within and across different academic backgrounds. In the first part of this paper, the media studies on virtual social networks and their relationships with building social capital are investigated. Following that, urban studies on the importance of inter-ethnic interactions between Malaysians in neighbourhoods will be discussed. Third, the theoretical debates and empirical research findings will be presented from the sociology perspective. In the discussion section, the results of each discipline will be crosschecked and evaluated by the current authors.

\section{Virtual Inter-Ethnic Relations and Social Capital: Media Studies}

In order to understand the virtual dimension of inter-ethnic relations in Malaysia, media studies have examined the function of online social networking 
communities in the formation of social capital. Online social communities have growing importance because the rise of online networking sites has helped the creation of new inter-group contacts and the maintenance of existing relationships. Also, some empirical studies have shown (see Adnan and Mavi [2015], Wan Jaafar [2014], and Yusof and Hashim [2013]) that online relations have the potential to increase offline face-to-face interactions. The media studies have therefore questioned how online communities affect the bridging social capital of their users by providing a common platform for them in which the members of diverse social groups can gather and communicate.

In the context of Malaysian society, online networking sites provide a multi-ethnic platform for the members of diverse ethnic groups to mingle with each other, which helps to build the bridging social capital of individuals. Adnan and Mavi (2015) therefore focused on the role of online communities in shaping the inter-ethnic interactions of Malaysians and investigated the role of Facebook regarding the connection between intensive Facebook usage and bridging social capital across different ethnic and age groups. Their quantitative research found no correlation between Facebook usage and bridging social capital. Even more, Facebook was not found to be an effective instrument for building contact between different ethnic groups.

Adnan and Mavi's (2015) findings showed that the number of contacts on Facebook did not necessarily imply a high level of bridging social capital of the user. In other words, having a broader network in virtual life does not always suggest an extensive network in reality because merely online communication was not found sufficiently adequate to create contacts across diverse social groups so that a virtual relationship could transform into bridging social capital (Adnan \& Mavi, 2015). The reason for that, as Adnan and Mavi (2015) pointed out, was that the 'quality' of interaction was more significant than its 'quantity'. However, because the data were obtained quantitatively, their findings do not provide in-depth information about which factors determine the quality of interactions taking place on Facebook.

Wan Jaafar (2014) shed light on the 'quality' issue of inter-ethnic interactions in online communities and the inherent bridging social capital of the users. Her findings suggested that even though social networks had a significant potential to build and extend the communication between members, their impact on the formation of social integration and bridging social capital across nonethnics remained limited. She also further highlighted that online communities might reinforce ethnic division and prejudices because of the language barrier and cultural and religious differences. In ethnically mixed online communities, such as USJ Subang Jaya and PJNet, Wan Jaafar (2014) found that the language 
preferences of users according to their ethnic affiliations caused social segregation. Non-Malay users preferred to speak English whereas Malay members chose Bahasa Malaysia as the medium of communication (Wan Jaafar, 2014). She also reported that Chinese and Indian users were more comfortable using English instead of Bahasa Malaysia, whereas for the Malays it was the reverse. For that reason, it can be remarked that language preference leverages the ethnic boundaries between Malaysians (Wan Jaafar, 2014). Furthermore, in online communications, the users can ignore each other's cultural, racial and religious differences, but these differences come out clearly in offline gatherings of the users. This pattern was particularly evident among the Malay users due to their religious sensitivities, such as halal food and the restrictions imposed by Islam on alcohol and nightlife (Wan Jaafar, 2014).

On the other hand, Yusof and Hashim's (2013) findings on the USJ Subang Jaya online network site contradict those of Wan Jaafar (2014). Yusof and Hashim's (2013) qualitative study was conducted with participants from the USJ Subang Jaya online community and showed positive results in terms of social interaction and the social capital building process of the users through this virtual network. Wan Jaafar (2014) showed that the over-representation of specific ethnic groups reinforces bonding social capital rather than the bridging form. Conversely, Yusof and Hashim (2013) claimed that the online community organised offline functions with the participation of the members of the community, which could enhance the community spirit and social interaction. They did not, however, specify in those social gatherings which ethnic group was represented the most, and which the least. In this regard, the findings are somewhat limited in implying that offline community gatherings build community spirit. Yusof and Hashim (2013) also found that the trust level of the community members was considerably low and that there were members who were prejudiced towards other users. Again, however, they did not elucidate which ethnic groups had higher levels of prejudice and towards which ethnic groups they were prejudiced.

Social networking sites have also been examined in terms of their impact on social solidarity in a community. Ridzuan, Bolong and Said (2017) contended that Malaysians were struggling to interact with non-ethnics and that this was a significant problem for social solidarity. The main reason for that could be the ethnocentrism towards non-ethnics due to stereotyping, mistrust, avoiding nonethnics and differential treatments for other ethnic group members (Ridzuan, Bolong \& Said, 2017). They also investigated the ethnocentric attitudes towards non-ethnics on social networking sites and found that the respondents had tendencies towards in-group solidarity and bonding social capital because they 
saw their own-ethnic group as having the best lifestyle, they trusted their fellowethnics more than others, and they practised differential treatments towards the non-ethnics. Nevertheless, the ethnocentric level of Malaysians was not found to have reached severe degrees (Ridzuan et al., 2017).

On the other hand, Ketab, Tamam and Bolong (2016) found different results from those of Ridzuan et al. (2017). They investigated the relationship between ethnocentrism and the online and offline inter-ethnic interactions of Malaysian students and found that ethnocentrism was negatively correlated with both online and offline interactions. More importantly, even among the students who had daily offline inter-ethnic interactions with non-ethnic peers, their online communication was at relatively lower levels. Ketab Tamam and Bolong (2016) commented that the respondents preferred not to enhance their social networks with peers from other ethnic groups but instead chose to make contacts within their ethnic circles rather than with multi-ethnic ones. The results showed that Malaysian students had significant ethnocentric attitudes towards peers of other ethnic groups which inhibited the trust and the cooperative behaviour between them (Ketab, Tamam, \& Bolong, 2016) and constrained the formation of bridging social capital and social cohesion (Ketab et al., 2016).

The empirical studies discussed above present inconsistent findings. Adnan and Mavi (2015) and Wan Jaafar (2014) found no positive correlation between participation in online communities and bridging social capital in real life whereas Yusof and Hashim (2013) claimed that online communities enhanced the social networks and social capital of their users. Similarly, Ridzuan et al. (2017) were more optimistic in terms of the role of social networking communities and suggested that virtual community users were more united and tolerant towards other ethnic groups. Nevertheless, Ketab et al. (2016) made the contrasting finding that the respondents tended to be more inward-looking on social networking platforms, which is by no means an indicator of unity or collaboration among Malaysians, as Ridzuan et al. (2017) suggested.

\section{Actual Inter-Ethnic Relationships and Social Capital: Urban Studies}

The discussion about the impact of ethnic diversity in the immediate residential settings on the level of social capital was amplified by Putnam (2007), who suggested that ethnic diversity leads to declining social solidarity and a reduced level of trust among the residents. His argument has been widely investigated in the literature in different country contexts. Even though there are studies which have supported his claims, this current review found various other reasons (see Gijsberts, Van Der Meer, \& Dagevos [2012], Letki [2008], Nannestad [2008], and Uslaner [2011]) for a low level of social capital and reinforcing the negative 
impact of ethnic diversity.

In the Malaysian context, urban studies have examined the impact of ethnic diversity by exploring the inter-group relationships of different ethnic groups in the neighbourhoods. Urban studies, in this regard, give broader insights into the dynamics of Malaysians' inter-ethnic interactions by revealing how the everyday relationships of ethnics are shaped in urban areas. It should be noted that the social capital concept was not used explicitly in the studies which were the subjects of this paper, but the variables which the urban studies focused on, namely social networks, trustworthiness and participation in residential facilities, coincide with social capital indicators. For that reason, urban studies on inter-ethnic relations in Malaysia have relevance for this paper.

Overall, the studies have shown that the diverse neighbourhoods provide opportunities for meaningful contact between the residents, which can create impacts in building closer bonds across different ethnic groups in Malaysia. The characteristics of residential areas are therefore of great importance from the urban studies point of view because the studies have shown that the inter-ethnic interactions and relationships of Malaysians vary in ethnically homogeneous and heterogeneous urban areas in terms of social solidarity and social cohesion in Malaysian society.

One of the seminal studies in this area is the work of Dali and Nordin (2010) who investigated Malaysians' perception of each other who were living in the same neighbourhood. The research was carried out in the Klang Valley area with 891 respondents. The results showed that the respondents had high levels of tolerance but that their involvement in residential functions remained limited. The respondents were aware that living together with other ethnic groups would help them to have a better understanding of the culture and lifestyle of other ethnicities, but they were nevertheless reluctant to live with other races side-byside. Dali and Nordin (2010) stated that the reason for this could be the lack of understanding of other ethnic groups' ways of life. Prejudices and the lack of opportunities for meaningful contact with non-ethnics were other possible factors causing an inward-looking attitude when dealing with others. Dali and Nordin (2010), therefore emphasised the importance of higher levels of heterogeneity within neighbourhoods which could increase the opportunities for inter-ethnic interaction.

In terms of the tolerance level of Malaysians, Husin, Malek and Gapor. (2012) found similar results to those of Dali and Nordin (2010). They studied urban dwellers in Kuala Lumpur, Selangor, Penang and Johor Bahru and found that even though the respondents accepted their neighbours' religious and cultural practices, they still preferred to live with their co-ethnics. Similarly, 
Ahmad and Syed Abdul Rashid (2003) reported that more respondents were willing to socialise with their co-ethnics than to mix with others amongst both Malay and Chinese respondents. Interestingly, even in ethnically mixed neighbourhoods, the closest friends of all the respondents came from the same ethnic group.

Ahmad and Syed Abdul Rashid (2003) compared respondents' interaction tendencies between ethnically mixed neighbourhoods and mono-ethnic neighbourhoods. Their findings showed that in ethnically mixed social settings, residents were more open to interacting with other ethnic groups than in ethnically homogenous neighbourhoods. Nevertheless, the respondents were reluctant to join in some social activities together with a non-ethnic neighbour, such as exchanging goods or going out on a picnic with them in both neighbourhoods. Ahmad and Syed Abdul Rashid (2003) suggested that this could possibly be explained by the religious differences between the ethnic groups, which made the Malaysians hesitant about mingling with each other socially.

The findings of urban studies have shown that they found something of a consensus in terms of the inter-ethnic relations of Malaysians in real life. As the studies showed, Malaysians overwhelmingly tended to socialise with fellowethnics. They remained hesitant and reluctant to interact with non-ethnics because of a lack of understanding of each other and significant religious or cultural differences. Moreover, inter-ethnic interactions were remarkably rare in mono-ethnic social settings compared with mixed areas, whereas ethnically mixed social settings provided more opportunities for their residents to interact with their neighbours of other ethnic groups. On the other hand, even in those settings, the studies found that multi-ethnic interactions had limitations when it came to particular social activities.

From the social capital perspective, it can be argued that multi-ethnic social settings play a significant role in providing common ground for meaningful contact and opportunities for bridging social capital to all residents from different ethnic groups. Nevertheless, inter-ethnic interactions in the neighbourhoods do not seem adequate for creating social trust among non-ethnic Malaysian residents and for extending their social networks. For that reason, the issue of why meaningful contact faces problems over transforming into social capital in the relationships of Malaysians should be further analysed.

\section{Inter-ethnic Relations and Social Capital: The Sociological Perspective}

Both media studies and urban studies have focused on inter-ethnic interactions at the micro level. Nevertheless, there is a broad literature discussing the impact 
of macro dynamics on individuals' social capital building processes. Income inequality between citizens, corruption and unequally distributed public spending have been found to be strongly correlated with the trust level of citizens and their social capital (Alesina \& La Ferrara, 2000; Bjørnskov, 2003; Delhey \& Newton, 2005). In this respect, social capital is created through the micro-level interactions of Malaysians, but its formation is also related to the topdown efforts which are formed and shaped by state policies at the macro level. This argument is similar to those studies based in the discipline of history where, since the colonial policy of divide and rule, famously articulated in the writings of the colonial administrator-cum-scholar Furnivall, the seeds of a Malayan plural society had been sown (see Furnivall [1944] and Milner [2003]).

The social capital concept has been the subject of sociology in the Malaysian social sciences. Some empirical studies have investigated the microlevel interactions of individuals in social life from the social capital formation perspective, whereas there have also been theoretical discussions about the possible causes of the low level of social solidarity and integration in Malaysian society.

Empirical studies examining the bridging social capital of Malaysians have merged with previous works on the inter-racial relations of Malaysians in order to increase our understanding of ethnic identities, ethnocentrism, mistrust and the commonly held racial prejudices which shape the inter-ethnic relations comprehensively in Malaysian society. Their major concern is to identify the obstacles which Malaysians come across in different aspects of social life. In this respect, the studies have mostly focused on the school or workplace environments and peer relations from diverse ethnic groups (see David \& Wendy Yee Mei Tien [2010], Nge [2010], and Lee and Muhammed Abdul Khalid [2016]). Their findings confirm the social segregation and the reluctance of Malaysians to interact with non-ethnics which urban studies have indicated.

Recent studies have provided extensive information about young Malaysians', particularly students', socialisation processes with non-ethnic peers, and their social capital levels. One important study was conducted by Tamam (2013), who examined the impact of ethnic identities and inter-ethnic interactions on the level of bridging social capital of the undergraduate students in a public university of Malaysia. The participants were students from Malaysia's three main ethnic groups, the Malays, Chinese and Indians. The preliminary findings showed that the students were not racially integrated and that their level of interracial bridging social capital was inadequate. Furthermore, their ethnic identities were still robust in the self-identification of Malay and Chinese students. He (2013) showed that Indians, who defined themselves by their national identity 
rather than their ethnic identity, had the highest bridging social capital whereas Malay students had the lowest. This was interpreted as a result of the minority/majority status of Indians and Malays in social life (Tamam, 2013).

Mohd conducted another quantitative study which investigated the interethnic interactions of students in secondary schools in Malaysia. His findings suggested somewhat similar results to those of Tamam (2013); each ethnic group preferred to study and/or socialise with their fellow-ethnics, or they sought help only from their friends from the same ethnic group. These are indications of the high level of bonding social capital of the students, nevertheless, as Mohd. Yusof (2014) remarked the increased level of interaction created a better relationship between non-ethnics. This is another finding which is in line with those of Tamam (2013).

On the other hand, the major factors inhibiting the bridging social capital of the students remained unanswered in the studies of both Tamam (2013) and Mohd. Yusof (2014). Tamam (2013), for example, suggested that the increases in the contact level of ethnics created positive outcomes on the students' perceptions about each other; therefore, the university's immediate environment could have been further improved by implementing systematic inter-racial programmes. Nevertheless, both Tamam (2013) and Mohd. Yusof (2014) overlooked the lack of intense connections and the mistrust between the students who were studying in the same school environment. Also, their research did not address the issue of what were the on-the-ground reasons which constrained the inter-ethnic interaction of students in schools, or why non-ethnic classmates needed an outsider motivation which forced them to mingle with each other.

The qualitative work of Harris and Han (2019) offered some explanations for the segregated relations of university students. They questioned young Malaysians' perception of 'others' and their inter-ethnic experiences shaped by the top-down efforts of the state, such as 1Malaysia programme, and found that there was a structural inequality between ethnic groups at the societal level which was formed by the social hierarchies based on ethnic identities, ethnic divisions and spatial segregations in schools, neighbourhoods and workplaces. The 1Malaysia programme had only highlighted the multi-ethnic characteristic of Malaysian society instead of acknowledging the real ethnic inequality problems at the societal level. Therefore, as Harris and Han (2019) pointed out, "until ethnic inequality is more adequately recognised and addressed, a deep and productive everyday mix cannot be possible, and everyday encounters frequently take the form of everyday racism" (p. 16). 


\section{Theoretical Perspectives on Ethnicity and Identity in Malaysian Studies}

Social capital is crucial in the Malaysian context because it elucidates the levels of cooperation between outgroup members and associations and the members of diverse social groups which are critical dynamics of social interaction (Uslaner \& Conley, 2003). The empirical studies examined here showed that ethnic/racial categories play a crucial role in forming and shaping the everyday relationships of Malaysians and also cause a low level of bridging social capital among Malaysians by impeding intergroup trust and common norms and values. Along with the empirical studies of the social capital and cohesion problems of Malaysians, the vital position of ethnic identities paved the way for theoretical discussions among scholars about the reasons for the wide acceptance of ethnic identifications over the overarching national identity.

According to Shamsul A. B. (1998) Malaysian social science has four academic paradigms in the examination of Malaysian social reality: ethnicity, class, culture and identity. Embong (2018) commented that culture and identity are relatively recent paradigms which were produced in the postcolonial era. From the social capital theory perspective, the ethnicity and identity paradigms have seemed to intertwine with each other in Malaysian society. The concept of social capital enables us to examine the extent of networks comprising either one particular or diverse social groups. In this respect, a person can obtain a single identity consisting of his/her ethnic affiliation, but he/she can also have multiple or hybrid identities embracing compound identities, including territorial identities, such as Sarawakian Chinese Christians.

The theoretical discussions on ethnicity and identity formation in Malaysian society vary from the single and broad ethnic identities of Malay, Chinese, Indian and Others (MCIO) to numerous mixed, sub-ethnic, religious and territorial identities. For example, Mandal (2001) emphasised the existence and efficacy of sub-identities underneath MCIO and Sathian and Ngeow (2014) highlighted the multiple and complex identities in their empirical study conducted in Kelantan. They showed that the identity structure of the Chinese minority combined their ethnic identity with a local, territorial orang Kelantan identity. On the other hand, Daniels (2010) argued that broad ethnic categories with constructed boundaries had served a function in mediating the power distribution in Malaysian society by demonstrating evidence in his empirical study on Chinese and Malay relationships in Melaka. In a similar vein, Leow (2016) drew attention to these collective Melayu and Cina identities and their instrumental function.

...the labels we know as Malayness and Chineseness are not perfectly 
formed single identities to be worn or removed like a hat, but disciplined, social creations, cognitive process or even mindsets and sociocognitive frames, which produces a certain lived reality. (p. 8)

Alternatively, Harris and Han (2019) combined the collective identity perspective with singular and individual identities in social reality by emphasising the importance of "clear ethnic categories" in the social interactions of Malaysians. They pointed out that even though these collective identities had been historically or politically created, they are negotiated, reconstructed and sometimes disrupted for the singular-ethnic identities by the ordinary people in social practice. For example, their data showed that Malaysians could strategically enact different ethnic identities depending on the situation to cope with the everyday racism which they encountered in social life. Therefore, contrary to the state-led efforts for social harmony and ethnic integration, the "implicit rules of the unequal multi-racial order" at the societal level could be applied in social life (Harris \& Han, 2019, p. 9). As a result, the responses of the ordinary Malaysians to the state-led integration efforts in negotiating multiculturalism, ethnic diversity and integration should also be taken into consideration in order to understand the social reality of Malaysian society.

Social groups, more specifically individuals, utilise their ethnicities for self-identification (Harris \& Han, 2019), but they can also extend and diversify the range of their identities by creating meaningful contact with outgroup members, the trust of other ethnic/religious groups, and the widely accepted norms and shared values within the community. From this perspective, social actors do not play a neutral role in the socialisation process. Instead, they accept, change, disrupt or reject the identity configurations imposed by the political agents. Ethnic or racial categories then become instrumental as socio-cognitive categories in order to negotiate the social position of social groups - ethnic groups in this case - and maintain the power struggle. As urban studies and media studies of online social networks have shown, ethnic identities function as a catalyst for protecting and recreating social hierarchies and ethnic inequalities, causing social segregation, and impeding the formation of bridging social capital among Malaysians. It can, therefore, be gathered from the literature that neither the collective ethnic categories nor the single identities are the reason for the low level of social capital and social segregation. Instead, as the example of Indian Malaysians' acceptance of national identity over ethnic identity has shown (Tamam, 2013), the strong ethnic identities are deployed to defend group boundaries in order to protect the privileges, special rights or the rights of exclusive access to the networks by using ethnic niches. 


\section{Conclusion}

The purpose of this article was to examine the empirical and theoretical discussions on ethnicity and social capital in the Malaysian context. Studies from three academic fields were examined; media studies, urban studies and sociology. Their findings were compared in order to elucidate the impact of ethnicity on building social capital process of Malaysians. Even though ethnicity has so far been one of the dominant paradigms in Malaysian studies investigated widely in historical, political, sociological and nation-building contexts, it has been shown in this paper that it is also related to the social capital concept explored in media and urban studies.

Putnam (2007) claimed a connection between ethnic diversity and the low level of social capital in a community. His assertion has been widely discussed in the literature in different country contexts. In the case of Malaysia, empirical studies have examined the social capital building process and the relationships of Malaysians from the ethnic diversity perspective. Overall, in line with Putnam's claim, the findings of these studies have revealed a negative correlation between ethnic diversity, social solidarity and bridging social capital; however, they have also found that meaningful interaction between different ethnic groups has created a positive impact on building bridging social capital between the members of different ethnic groups.

Media studies have provided information about virtual interactions through online social networks, whereas urban studies have given insights into the actual, real-life dimension of inter-ethnic relations of Malaysians. The majority of the empirical studies examined in this paper found that a strong ethnic identification among Malaysians was prevalent and that it impedes interethnic interactions between different ethnic groups. Even on online social networks, in which the users are anonymous and can hide their ethnic and religious identities most of the time, ethnic boundaries were found to be evident and effective in shaping the users' interactions with each other. Similarly, as urban studies have shown, the interaction patterns of Malaysians are shaped predominantly by the ethnic identities in ethnically mixed urban settings. As a result, the majority of the studies indicated that the bonding social capital and ingroup solidarity of Malaysians shaped along the ethnic lines were stronger than their bridging social capital.

Theoretical discussions, on the other hand, have argued about the ethnic identity formation of Malaysians. Some scholars have highlighted the importance of the dominant MCIO (Malay, Chinese, Indian and Others) ethnic categories whereas others found empirical evidence showing the significance of sub-ethnic categories and complex multiple identities. Studies of the social 
capital building process have revealed, however, that ethnicity and identity are not stand-alone paradigms. As the historical and political studies have indicated, ethnic identities might have been created by the colonial rulers or political elites and imposed on the ordinary people; nevertheless, as Harris and Han (2019) demonstrated, they are mediated and reshaped in the process of inter-ethnic interactions by Malaysians in the social reality. As a result, it can be argued that ethnic identities - either single or complex ones - have an instrumental role in protecting and recreating group boundaries and regulating the relationships with outgroups. In this regard, the findings of the present article suggest that the social capital concept has the potential to provide an alternative paradigm to the theoretical discussions in Malaysian studies by combining the dominant paradigms, particularly ethnicity and identity in the Malaysian case. The concept, by focusing on the trust relations of individuals, common norms and values in the community and the quality of networks of individuals, can help to avoid the strong pressure of historical understandings imposed by the dominant paradigms of ethnicity and class. The extensive usage of the mainstream ethnic categories in the Malaysian literature, for example, can easily be observed. Because the social capital concept gives scholars flexibility, it can pave the way for a different approach to the examination of the functions of ethnicity, class, culture and identities in the process of building trust relations and networks across diverse social groups in society. Malaysian society should, therefore, be further examined from the social capital theoretical paradigms standpoint.

The majority of the empirical studies which have investigated social capital have been quantitative studies, but when it comes to clarifying the underlying reasons for the reluctance of Malaysians to mingle with each other, the explanations given by quantitative studies remain speculative. Quantitative studies provide extensive data by identifying the level of social capital whereas qualitative studies acquire more comprehensive data illuminating the fundamental causes of the obstacles impeding the inter-ethnic interactions of Malaysians (see Tamam [2013], and Harris and Han [2019]). In this respect, future qualitative studies conducted in this area will be significant for understanding the problem of the low level of social capital in Malaysian society.

\section{Acknowledgements}

This paper is an extension of the first author's master's dissertation completed in 2019 at the Department of Southeast Asian Studies, University of Malaya. Research conducted for this paper was facilitated through a graduate scholarship from the National Ministry of Education of the Republic of Turkey. We wish to thank both the Malaysian and Turkish institutions for their support. 


\section{References}

Adnan, H. M., \& Mavi, S. R. (2015). Bridging Social Capital on Facebook as a Platform: A Case Study of Malaysian College Students. Asian Social Science, 11(15), 1-9.

Ahmad, N., \& Syed Abdul Rashid, S. N. (2003). Social Interaction in Urban Areas: A Case Study of Mixed and Mono-Ethnic Neighbourhoods in Kuala Lumpur. Pertanika: Journal of Social Sciences \& Humanities, 11(2), 107-118.

Alesina, A., \& La Ferrara, E. (2000). Participation in Heterogeneous Communities. Quarterly Journal of Economics, 115(3), 847-904.

Alesina, A., \& La Ferrara, E. (2002). Who Trusts Others? Journal of Public Economics, 85(2), 207-234.

Bjørnskov, C. (2003). The Happy Few: Cross-Country Evidence on Social Capital And Life Satisfaction. Kyklos, 56(1), 3-16.

Brehm, J., \& Rahn, W. (1997). Individual-Level Evidence for the Causes and Consequences of Social Capital. American Journal of Political Science, 41(3), 999-1023.

Costa, D. L., \& Kahn, M. E. (2003). Civic Engagement and Community Heterogeneity: An Economist's Perspective. Perspectives on Politics, 1(1), 103-111. https://doi.org/10.1017/S1537592703000082

Dali, M., \& Nordin, N. (2010). Is There an Integrated Society in Urban Neighbourhoods of Klang Valley in Malaysia? Journal of Sustainable Development, 3(3), 266-274.

Daniels, T. P. (2010). Urban Space, Belonging, and Inequality in Multi-Ethnic Housing Estates of Melaka, Malaysia. Identities, 17(2-3), 176-203.

David, M. K., \& Wendy Yee Mei Tien. (2010). Perception of Ethnic Otherness: A Study of Malaysian Children. In M. K. David, J. McLellan, Ngeow Yeok Meng, Lean Mei Li, \& Wendy Yee Mei Tien (Eds.), Ethnic Relations and Nation Building: The Way Forward (pp. 83-200). Petaling Jaya: Strategic Information and Research Development Centre.

Delhey, J., \& Newton, K. (2005). Predicting Cross-National Levels of Social Trust: Global Pattern Or Nordic Exceptionalism? European Sociological Review, 21(4), 311-327.

Embong, A. R. (2018). Ethnicity and Class: Divides and Dissent in Malaysian Studies. Southeast Asian Studies, 7(3), 281-307.

Farouk, A., \& Zaini, M. A. B. (2007). State-Induced Social Capital and Ethnic Integration: The Case of Rukun Tetangga in Penang, Malaysia. Kajian Malaysia, 15(1), 41-60.

Furnivall, J. S. (1944). Colonial Policy and Practice: A Comparative Study of Burma 
and Netherlands India. New York: New York University Press.

Gijsberts, M., Van Der Meer, T., \& Dagevos, J. (2012). “Hunkering Down” in Multi-Ethnic Neighbourhoods? The Effects of Ethnic Diversity on Dimensions of Social Cohesion. European Sociological Review, 28(4), 527537.

Hall, P. A. (1999). Social Capital in Britain. British Journal of Political Science, 29(3), 417-461.

Harris, A., \& Han, A. (2019). 1Malaysia? Young People and Everyday Multiculturalism in Multiracialized Malaysia. Ethnic and Racial Studies, 119.

Hefner, R. W. (2001). Introduction: Multiculturalism and Citizenship in Malaysia, Singapore, and Indonesia. In R. W. Hefner (Ed.), The Politics of Multiculturalism: Pluralism and Citizenship in Malaysia, Singapore, and Indonesia (pp. 1-58). Honolulu: University of Hawai'i Press.

Husin, A., Malek, N. M., \& Gapor, S. A. (2012). Cultural and Religious Tolerance and Acceptance in Urban Housing: A Study of Multi-Ethnic Malaysia. Asian Social Science, 8(2), 112-118.

Ketab, S. M. G., Tamam, E. B., Bolong, J. B., \& Sharif, S. P. (2016). Interethnic Bridging Social Capital and the Significance of Ethnocentric Interethnic Interaction Within Malaysian Universities. Journal of Intercultural Communication, $42 . \quad$ Retrieved from https://www.immi.se/intercultural/nr42/ketab.html

Lee, H. A., \& Muhammed Abdul Khalid. (2016). Discrimination of High Degrees: Race and Graduate Hiring in Malaysia. Journal of the Asia Pacific Economy, 21(1), 53-76.

Leow, R. (2016). Taming Babel: Language in the Making of Malaysia. Cambridge: Cambridge University Press.

Letki, N. (2008). Does Diversity Erode Social Cohesion? Social Capital and Race in British Neighbourhoods. Political Studies, 56(1), 99-126.

Levi, M. (1996). Social and Unsocial Capital: A Review Essay of Robert Putnam's Making Democracy Work. Politics and Society, 24(1), 45-55.

Mandal, S. K. (2001). Boundaries and Beyond. In R. W. Hefner (Ed.), The Politics of Multiculturalism: Pluralism and Citizenship in Malaysia, Singapore and Indonesia (pp. 141-164). Honolulu: University of Hawai'i Press.

Milner, A. (2003). Who Created Malaysia's Plural Society? Journal of the Malaysian Branch of the Royal Asiatic Society, 76(2), 1-24.

Mohd. Yusof, N. (2014). Patterns of Social Interaction Between Different Ethnic Groups in Malaysian Secondary Schools. Jurnal Pendidik Dan Pendidikan, 21, 149-164. 
Nannestad, P. (2008). What Have We Learned About Generalized Trust, If Anything? Annual Review of Political Science, 11(1), 413-436.

Nge, C. (2010). Malaysian University Students Discuss Race and Ethnicity. In M. K. David, J. McLellan, Ngeow Yeok Meng, Lean Mei Li, \& Wendy Yee Mei Tien (Eds.), Ethnic Relations and Nation Building: The Way Forward (pp. 271-232). Petaling Jaya: Strategic Information and Research Development Centre.

Ostrom, E. (2000). Social Capital: A Fad or a Fundamental Concept? In P. Dasgupta \& I. Serageldin (Eds.), Social Capital: A Multifaceted Perspective (pp. 172-215). Washington, D.C.: The World Bank.

Paxton, P. (2006). Social Capital and Democracy: An Interdependent Relationship. American Sociological Review, 67(2), 254-277.

Paxton, P. (2007). Association Memberships and Generalized Trust: A Multilevel Model Across 31 Countries. Social Forces, 86(1), 47-76.

Putnam, R., Leonardi, R., \& Nonetti, R. (1993). Making Democracy Work: Civic Traditions in Modern Italy. Princeton, New Jersey: Princeton University Press.

Putnam, R. D. (2000). Bowling Alone: The Collapse and Revival of American Community. New York: Simon \& Schuster.

Putnam, R. D. (2007). E Pluribus Unum: Diversity and Community in the Twenty-First Century. Scandinavian Political Studies, 30(2), 137-174.

Ridzuan, R. A., Bolong, J., \& Said, A. M. A. (2017). The Level of Cyber Ethnocentrism Among Multiethnic in Malaysia. Academic Journal of Business and Social Sciences, 1(1), 1-14.

Sathian, M. R., \& Ngeow, Y. M. (2014). Essentialising Ethnic and State Identities: Strategic Adaptations of Ethnic Chinese in Kelantan, Malaysia. Asian Studies Review, 38(3), 385-402.

Shamsul, A. B. (1998). Ethnicity, Class, Identity, Culture or Identity? Competing Paradigms in Malaysian Studies. Akademika, 53(1), 33-60.

Tamam, E. (2013). Interracial Bridging Social Capital Among Students of a Multicultural University in Malaysia. Journal of College Student Development, 54(1), 85-97.

Uslaner, E. M. (2011). Trust, Diversity, and Segregation in the United States and the United Kingdom. Comparative Sociology, 10(2), 221-247.

Uslaner, E. M., \& Conley, R. S. (2003). Civic Engagement and Particularized Trust: The Ties That Bind People to Their Ethnic Communities. American Politics Research, 31(4), 331-360.

Wan Jaafar, W. M. (2014). Exploring Social Capital in Malaysian Online Ethnic Communities. The Macrotheme Review, 3(2), 170-187. 
Yusof, S. A. M., \& Hashim, K. F. (2013). Exploring the Formation of Social Capital in a Malaysia Virtual Community. Journal of Community Informatics, 10(1). Retrieved from http://ci-journal.net/index.php/ciej/article/view/932 